\section{Temporal variations in dung beetle (Coleoptera: Scarabaeidae) assemblages in Kurukshetra, Haryana, India}

\section{Nidhi Kakkar ${ }^{1}$ \& Sanjeev K. Gupta ${ }^{2}$}

1,2 Kurukshetra University, Kurukshetra, Haryana 136119, India Email: ${ }^{1}$ nidhikakkar12@yahoo.com

Dung beetles are taxonomically as well as functionally very important component of terrestrial ecosystem. They are nature's scavengers, burying quantities of dung into the ground and thus cleaning up the earth surface of excreta left mostly by large and medium sized herbivorous mammals (Hingston 1923). They help in maintaining the environment by utilizing and dispersing the organic waste (Mittal \& Yadav 1979; Mittal 1993b). These insects are important for the dynamics of matter in ecosystem, because they remove detritus of the soil surface (Halffter \& Matthews 1966).

The dung beetle communities are excellent models to evaluate and to monitor to what degree the changes in the vegetation alter the animal communities (Halffter \& Favila $1993)$.

India has a rich and diverse fauna of dung beetles. This paper is an effort towards the knowledge of variations in the dung beetle assemblages temporally, in terms of species composition, species richness, abundance and diversity.

\section{Methods}

Sampling site: Pitfall trapping of dung beetles was conducted from April to September in a small area, $15 \mathrm{~km}$ away from Kurukshetra, which is situated at $29^{\circ} 58^{\prime} \mathrm{N} \& 76^{\circ} 52^{\prime} \mathrm{E}$, approximately $250 \mathrm{~m}$ elevation and is part of the Punjab plains. The area was covered with small herbs, shrubs and some tree strands. The area was frequently visited by cattle for foraging.

Trapping Methods: The pitfall trap design was based on that of Tyndale-Biscoe et al. (1981). A set of traps consisted of five replicate traps. It is a tin can of $1-1 \frac{1}{2}$ litre capacity. Fresh cattle dung was supported on a plate at the top of the trap. The trap contents were collected after $24 \mathrm{hrs}$. of fixing the traps. Lobo et al. (1998) demonstrated that the use of only

Date of publication (online): 26 September 2009

Date of publication (print): 26 September 2009

ISSN 0974-7907 (online) | 0974-7893 (print)

Editor: Kailash Chandra

\section{Manuscript details:}

Ms \# 02075

Received 06 October 2008

Final received 26 May 2009

Finally accepted 02 September 2009

Citation: Kakkar, N. \& S.K. Gupta (2009). Temporal variations in dung beetle (Coleoptera: Scarabaeidae) assemblages in Kurukshetra, Haryana, India. Journal of Threatened Taxa 1(9): 481-483.

Copyright: (C) Nidhi Kakkar \& Sanjeev K. Gupta 2009. Creative Commons Attribution 3.0 Unported License. JoTT allows unrestricted use of this article in any medium for non-profit purposes, reproduction and distribution by providing adequate credit to the authors and the source of publication.

\section{OPEN ACGESS | FREE DOWNLOAD}

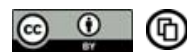

four pitfall traps sampled most species present at a site (between $60 \& 70 \%$ species, which corresponded to a $89 \& 93 \%$ abundance range, respectively).

\section{Data Analysis}

All trapped beetles were identified up to species level with the help of identification keys by Arrow (1931), Gupta (1986) and Mittal (1993a). To compare assemblages and constituent species, variation in monthly assemblages was described by parameters that include species richness, monthly changes in assemblage, composition and diversity. Weather and availability of additional dung can affect the number of species and individuals (Lobo et al. 1998). We studied $\alpha$ diversity by calculating the Margalef index $\left(\mathrm{D}_{\mathrm{M}}\right)$, as this balances the richness by the beetle numbers. $\mathrm{D}_{\mathrm{M}}=(\mathrm{S}-1) / \mathrm{In} \mathrm{N}$, where $\mathrm{S}$ is the number of species, $\mathrm{N}$ is the number of trapped individuals. One advantage of this index is the simplicity of the calculation.

\section{Results}

Data generated in this study showed 7668 individuals belonging to 23 species and three subfamilies Hybosorinae (1 sp.), Aphodiinae (5 spp.) and Scarabaeinae (17 spp.). From the weekly pooled data it was found that Aphodius. campestris accounting maximum proportional abundance (0.51) of total collected individuals and found to be the most abundant species. Onthophagus falsus and Aphodius lividus were the second and third most abundant species collected from the site (Table 1; Fig. 1).

\section{Seasonality}

Maximum number of beetles $(95.65 \%$ of total species and $52.58 \%$ of total individuals) were captured in June. Minimum $43.48 \%$ of total species and $0.57 \%$ of number of individuals were found in the month of April (Fig. 2). It was found that initially the assemblage showed lowest species richness and abundance which gradually increased till June. Then the richness was decreased in July and August and then raised in September (Fig. 2). This variation may be due to variable daily weather factors. Hill (1993) reported simple seasonal pattern in the Australian wet tropics, similar to other tropical regions with distinct wet and dry seasons (Janzen 1983).

Out of 23 species recorded, only six species (Aphodius urostigma, Drepanocerus sinicus, Caccobius vulcanus, Onthophagus catta, Onthophagus quadridentatus and Onthophagus falsus) were found throughout the collection period and of these, three species (Rhyssemus germanus, Gymnopleurus parvus, Gymnopleurus miliaris) were found once in whole the collection period. $43.48 \%$ species showed their peak of abundance in the month of June (Aphodius campestris, Onthophagus spinipes, Oniticellus pallipes, Oniticellus pallens, Caccobius vulcanus, Caccobius ultor, Onthophagus ramosellus, Onthophagus bonasus, Onthophagus quadridentatus and Onthophagus mopsus). Davis (1996) also observed the seasonal fluctuations in the size and composition of coprophagous beetle community.

\section{Diversity}

It was found to be greatest in the month of August (2.55), when $78.26 \%$ of species and $10.28 \%$ of individuals were present. The calculated lowest diversity was in the month of July (1.67) when $56.52 \%$ of species and $17.48 \%$ individuals were present. 


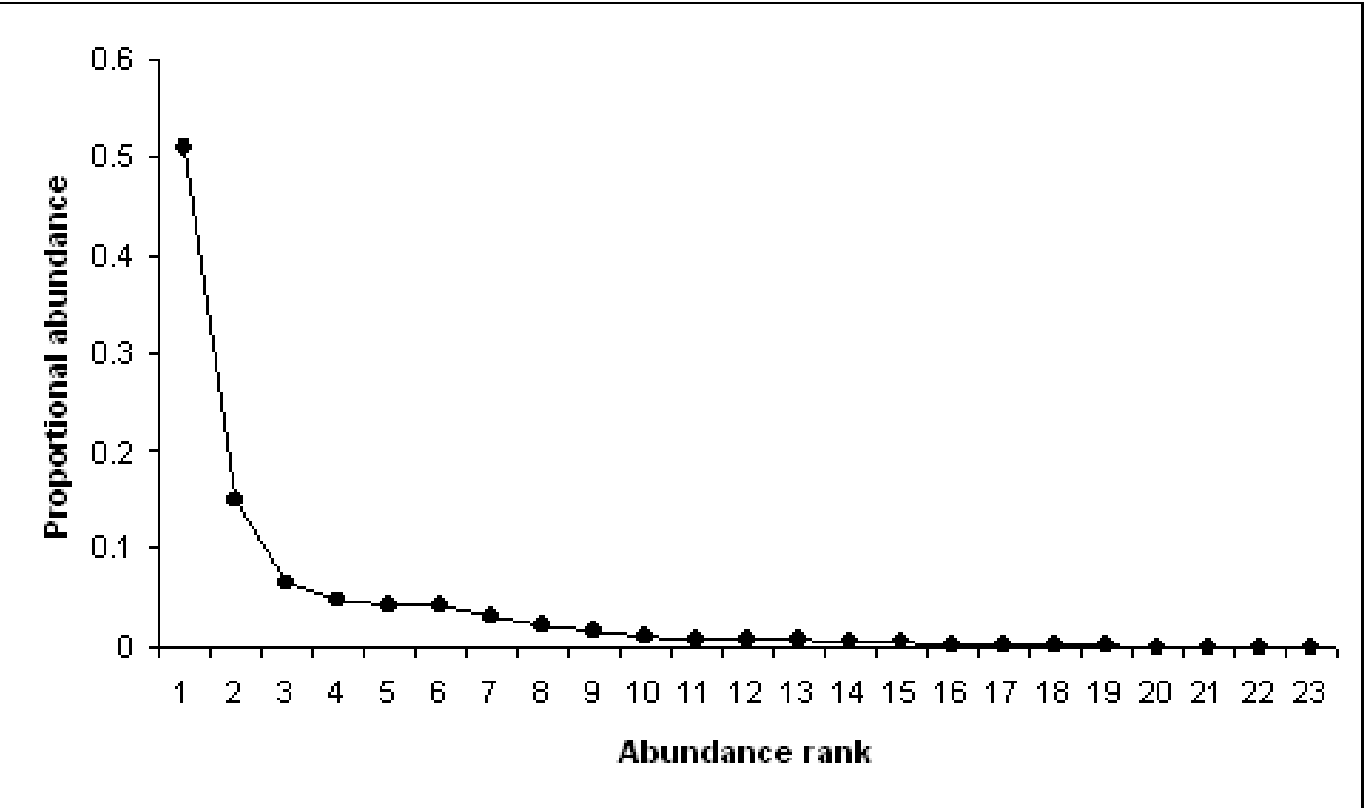

Figure 1. Proportional abundance distribution of different species in rank abundance curve

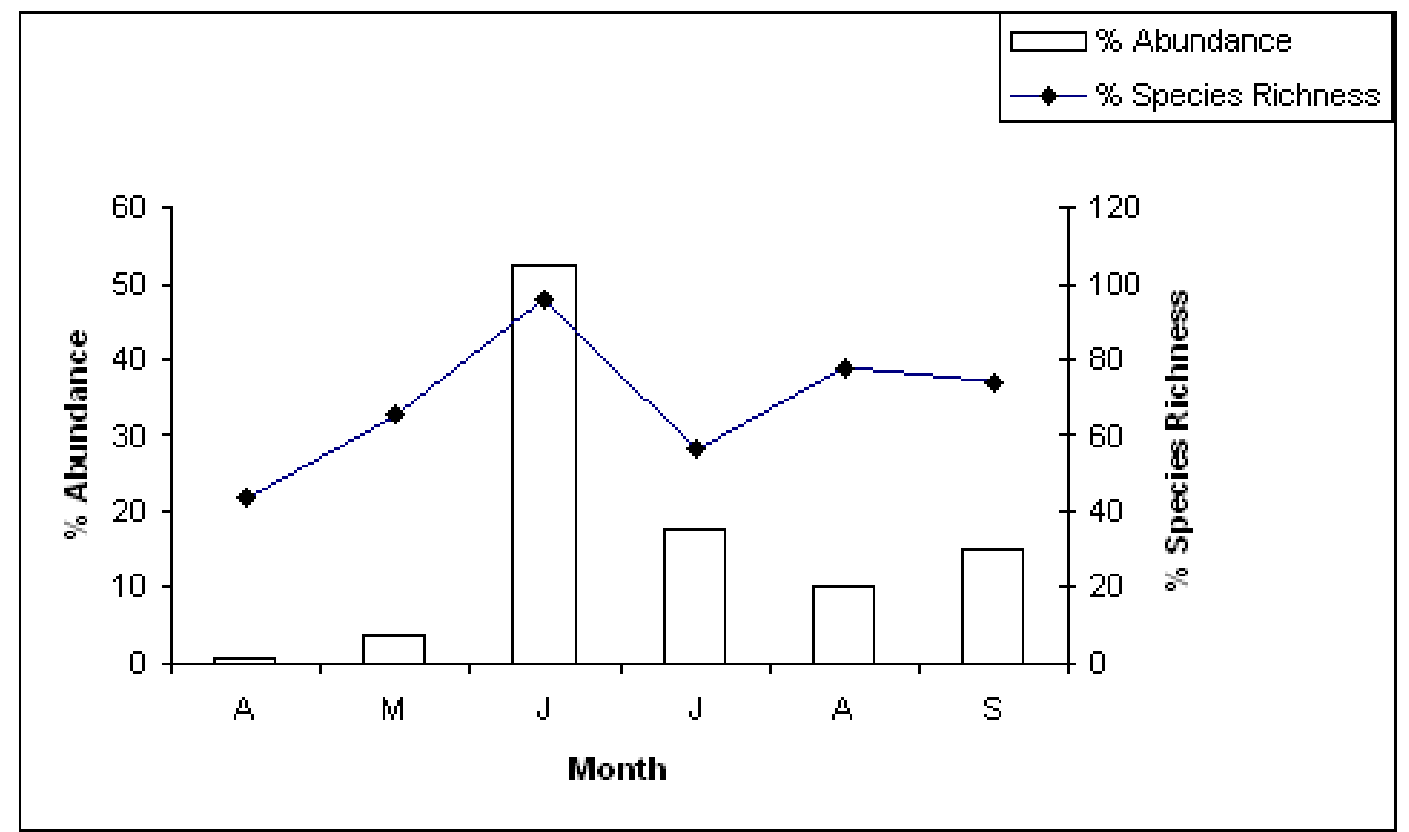

Figure 2. Temporal variations in the \% species richness and abundance

\section{Conclusion}

Based on the results of this study, it is concluded that the dung beetle assemblage is an ever changing structure. Out of the three subfamilies, Scarabaeinae (17 species) is the dominant subfamily. Aphodius campestris with the proportional abundance 0.51 shows its dominance in the assemblage. Most of the species $(95.65 \%)$ and individuals $(52.58 \%)$ were found in the month of June. So dung beetle seasonality suggests that the activity is greatest in June in terms of number of species and number of individuals and most of the species show their peak activity in June (Aphodius campestris, Caccobius vulcanus, Caccobius ultor, Onthophagus ramosellus, Onthophagus bonasus and Onthophagus quadridentatus). Assemblage structure depends on daily changing weather factors, species richness and individual abundance of a species (63.81\% individuals of Aphodius campestris in June and 25\% in May) forming an assemblage. Increase or decrease in individual abundance of a species affects the mean abundance of an assemblage (increased abundance of Aphodius campestris in June disturbs the mean value of the catch). Diversity is also found to be affected by season. The distribution of dung beetle species and abundance is not uniform throughout the study period, the assemblages vary temporally.

\section{References}

Arrow, G.J. (1931). The Fauna of British India including Ceylon and Burma, 
Table 1. Proportional abundance of different species

\begin{tabular}{lll}
\hline & Species & $\begin{array}{l}\text { Proportional } \\
\text { Abundance }\end{array}$ \\
\hline 1 & Aphodius campestris Mittal & 0.51 \\
2 & Onthophagus falsus Gill. & 0.15 \\
3 & Aphodius lividus (Oliv.) & 0.07 \\
4 & Onthophagus quadridentatus (Fabricius) & 0.05 \\
5 & Caccobius vulcanus (Fabricius) & 0.04 \\
6 & Onthophagus catta ( Fabricius) & 0.04 \\
7 & Caccobius ultor (Sharp) & 0.03 \\
8 & Aphodius urostigma Harold & 0.03 \\
9 & Oniticellus pallens (Oliv.) & 0.02 \\
10 & Drepanocerus sinicus Harold & 0.01 \\
11 & Oniticellus pallipes (Oliv.) & 0.01 \\
12 & Onthophagus mopsus (Fabricius) & 0.01 \\
13 & Gymnopleurus miliaris (Fabricius) & 0.01 \\
14 & Gymnopleurus parvus (MacL.) & 0.01 \\
15 & Onthophagus bonasus (Fabricius) & 0.01 \\
16 & Drepanocerus setosus (Wied.) & 0.004 \\
17 & Aphodius liesenfeldti Petrov. & 0.004 \\
18 & Onthophagus ramosellus Bates & 0.003 \\
19 & Rhyssemus germanus( L.) & 0.002 \\
20 & Onitis philemon Fabricius. & 0.001 \\
21 & Onthophagus centricornis (Fabricius) & 0.001 \\
22 & Oniticellus spinipes Roth. & 0.001 \\
23 & Hybosorus orientalis Westw. & 0.001 \\
\hline
\end{tabular}

Col. Lamella. III (Coprinae). Taylor and Francis, London, 428pp.

Davis, A.L.V. (1996). Diel and seasonal community dynamics in an assemblage of coprophagous, Afrotropical, dung beetles (Coleoptera: Scarabaeidae s. str., Aphodiidae and Staphylinidae: Oxytelinae). Journal of African Zoology 110:290-308.

Gupta, A.K. (1986). Studies on dung beetles (Coleoptera: Scarabaeidae: Laparosticti) of North West India. PhD Thesis, Kurukshetra University, Kurukshetra.
Halffter, G. \& E.G. Matthews (1966). The Natural History of dung beetles of subfamily Scarabaeinae (Coleoptera, Scarabaeidae). Folia Entomoogica. Mexicana 12-14: 3-312.

Halffter, G. \& M.E. Favila (1993). The Scarabaeinae (Insecta: Coleoptera) an animal group for analyzing, inventory and monitoring biodiversity in tropical rainforest and modified landscapes. Biology International 27: 15-23.

Hill, C.J. (1993). The species composition and seasonality of an assemblage of tropical Australian dung beetles (Coleoptera: Scarabaeidae: Scarabaeinae). Australian Entomologist 20: 121-126.

Hingston, R.W.G. (1923). A Naturalist in Hindustan. H.F. and G. Witharby, London, 292pp.

Janzen, D.H. (1983). Seasonal change in abundance of large nocturnal dung beetles (Scarabaeidae) in a Coasta Rican deciduous forest and adjacent horse pasture. Oikos 41:274-283.

Lobo J.M., J.P. Lumaret \& P. Jay-Robert (1998). Sampling dung beetles in the French Mediterranean area; effects of abiotic factors and farm practices. Pedobiologia 42: 252-266.

Mittal, I.C. (1993a). New Aphodiinae species (Coleoptera: Scarabaeidae) from India. Journal of Entomological Research 17(4): 239-245.

Mittal, I.C. (1993b). Natural Manuring and soil conditioning by dung beetles. Tropical Ecology 34(2): 150-159.

Mittal, I.C. \& P.S. Yadava (1979). Role of Coprophagous beetles in nutrient cycling. Geobios 6: 70-73.

Tyndal-Biscoe, M. M.M.H. Wallace, \& J.M. Walker (1981). An ecological study of an Australian dung beetle, Onthophagus granulatus Boheman (Coleoptera: Scarabaeidae), using physiological age-grading techniques. Bulletin of Entomological Research 71: 137-152.

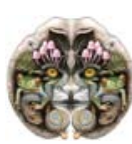

